\title{
A Double Seam Profile Tracking Automation Method for Cylindrical Welding Technique
}

\author{
Muciz ÖZCAN, Ahmet SAMANCl, Ahmet CAN
}

\begin{abstract}
This paper introduces a new method related to the joining of the metal pieces using cylindrical welding technique by determining double seam profile tracking. With the help of this method, solid and stabile welding quality is achieved on the applied materials. For this aim, a welding oscillator is implemented. The cylindrical welding operation is carried out properly on the applied metal pieces with the aid of two laser sensors, which find and eliminate eventual joining faults. Firstly, the position of the welding region is determined using the first laser sensor. After the welding process is done, a second laser sensor is used to check for the detection and elimination of the possible welding faults, so that a high quality welds can be performed. With the suggested cylindrical welding technique, only one special welding is required that makes the whole process more environment and budget friendly. Furthermore, the required energy and time for the welding operation are reduced significantly compared to the conventional manual welding. Moreover, consumption of hazardous gases, which are needed for protective shielding during the welding process such as carbon dioxide $\left(\mathrm{CO}_{2}\right)$, electric energy and electrode mass, were reduced greatly due to the elimination of the unnecessary welding operations.
\end{abstract}

Keywords: energy saving; laser profile sensors; welding; welding oscillator

\section{INTRODUCTION}

Over the past decades, there has been a dramatic increase in the Earth's average surface temperature largely due to excessive release of the greenhouse gases such as $\mathrm{CO}_{2}$. According to the scientific results, the amount of $\mathrm{CO}_{2}$ in the atmosphere has increased remarkably with the growing potential of the industrial productions. The increased amount of $\mathrm{CO}_{2}$ emission into the atmosphere could lead to global warming which is one of the most challenging environmental problems of our time mentioned by Rose et al., Kaygusuz, and Özcan et al. [13].

Global warming and its resulting climate changing effect are directly related with the increasing of energy consumption. About $1 \mathrm{~kg} \mathrm{CO} 2$ which makes $0.546 \mathrm{~m}^{3}$ volumes at room temperature and standard pressure $\left(25^{\circ} \mathrm{C}\right.$, $1 \mathrm{~atm})$ is released to the atmosphere for each $1 \mathrm{kWh}$ of energy generation. Similarly, after burning process of the combustion gases such as methane $\left(\mathrm{CH}_{4}\right)$ or propane $\left(\mathrm{C}_{3} \mathrm{H}_{8}\right)$, forms about $0.275 \mathrm{~m}^{3}$ of $\mathrm{CO}_{2}$ investigated by Jacobson et al [4]. Therefore, it is crucial to manage the energy consumption in the most efficient way and to reduce the forming of these harmful gases to prevent the serious environmental impacts $[5,6]$ on the entire world.

Welding is an important process for joining of metal pieces in many industrial sections. One of the most common methods among all welding techniques is arc welding due to the low price, simplicity and suitability for many kinds of metals and alloys. It is applied for joining of the metal pieces using electrical current which generates heat. The applied current passes from the used welding machine through the torch and electrode to the metal piece, forming an arc, which creates more than $3300{ }^{\circ} \mathrm{C}$. Either direct current (DC) or alternating current $(\mathrm{AC})$ can be used to perform the required welding operation with suitable electrodes. For the protection of the welding region and homogenous welding quality, some kind of shielding gases such as $\mathrm{CO}_{2}$ should be applied during the welding operation investigated by Gülenç et al. and Akorede et al. $[6,7]$. There are many previous works carried out on this area Reichelt et al. [8] such as electron beam welding using laser technology in structural metals in a wide range of between $0.025 \mathrm{~mm}$ and $300 \mathrm{~mm}$ thicknesses; effects of protecting gas on metal arc welding; weld metal composition forming during laser welding for aluminum alloy; and laser wire welding works based on robot and tracking sensor for many kinds of ship building studied by Frazier and Zhao et al. and Özcan [9-11].

On the other hand, the welding automation is an important subject for researchers and industrial companies. In an industrial application context, welding machines need to be connected to robot control systems to enable full automation of the welding process [12-13]. The determining of the welding seam and adaptively control of the welding torch and the welding parameters is an important subject for obtaining a fast and perfect welding seam. Current industrial welding robots are mostly articulated arms with a pre-programmed set of movement, which lack the intelligence skilled human welders possess. Liu and Zhang succeed about the human welder's control of the 3-D weld pool surface of an autogenous GTAW welding process using travel speed adjustment is learned and transferred to a welding robot in order to perform automated welding tasks [14-15].

This paper discusses fully automated cylindrical arc welding technique that uses a welding power supply to make an electric arc between an electrode and the metal pieces to get the melting point. At the same time, minimizing of the energy consumption and preventing of the dangerous gases during the joining process of the metal pieces using cylindrical welding technique by determining double seam profile tracking were studied. The advantages of this technique on the traditional welding methods were explained in detail. With the help of the welding manipulator performed in the light of this study, high quality, fully automated welding was achieved.

The welding quality of pressure vessels such as LPG, CNG fuel-gas tanks and hydraulic cylinders are very important because of the fatigue, explosion and leakage risk [16]. So the welding of these pressure vessels must be applied carefully and according to desired standards. The welding by human hand does not propagate a precise and sustainable welding seam. Especially in serial production systems, obtaining a standard and increased welding quality, minimizing the welding time, welding 
consumptions (energy, gas, and electrodes) are very important for production costs. In some primitive systems the rotational parts can be welded by rotating the parts by a simple mechanism in a constant velocity and bring closer the torch to the part surface. In these primitive systems the aperture-clearance of the welded part and the weld filling of the seam cannot be controlled in real time of the welding. On the other hand Traditional manual welding has many disadvantages over cylindrical welding technique such as excessive deformations due to the overlaps, roughness and faulty welding operation [17-21]. Consequently, it comes up undesired poor welding performance. For this aim in this work, a new adaptive welding system was developed. This novel system controls the welding seam quality real time and obtains a standard and increased quality welding seam and minimizes the welding costs.

The developed and the old primitive manual welding systems were compared with each other. The used electrode, gas volume, electrical energy consumption, welding time and the welding quality were the comparing parameters.

\section{MATERIALS AND METHODS}

In this study, a new method related to the joining of the metal pieces was presented using cylindrical welding technique by detecting double seam profile tracking. Using this method, solid and stabile welding quality was achieved on the applied materials. The schematic of the entire system is shown in Fig. 1.

The operational principle of the cylindrical welding technique is explained as follows. The required data for the welding area of the metal pieces are obtained with the help of the laser profile sensors (LPS: LPS1 and LPS2). The welding operation for the determined area of the metal pieces is performed using the welding torch that can be controlled with two dimensional step motors. The welding speed of the metal pieces can be set with the help of the three-phase squirrel-cage induction motor which is controlled by a Programmable Logic Controller (PLC). LPS1 is located in a safe distance from welding torch for protecting it from the hot steam or some molten metal pieces that can occur during the welding operation.

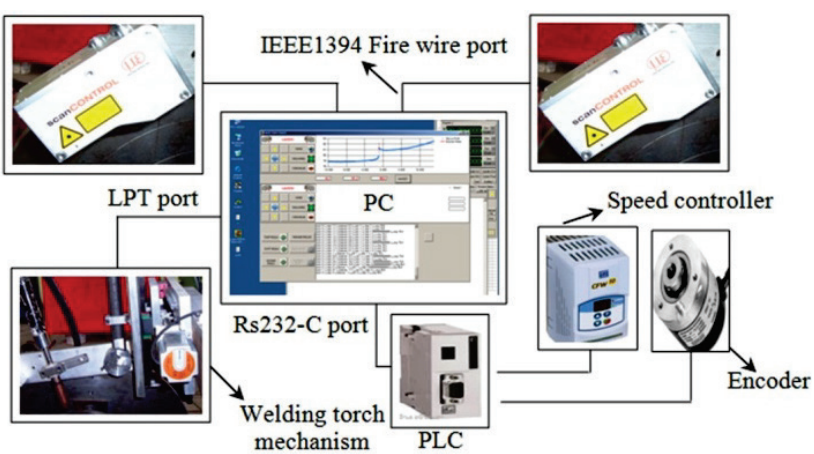

Figure 1 The entire system connection with PC for welding process

Similarly, LPS2 is placed at a safe location. The position data between the welding torch and used sensors are transferred to the PC over a PLC connected encoder. The purpose of the LPS2 sensor is to get the visual image of the welding area after the welding process, and check whether the required welding quality is obtained.

Seam tracking system includes a Metal Inert Gas (MIG) welding machine, an industrial LPS, a biaxial motor-controlled manipulator to control the position of welding torch, a mechanism to turn the sheet metal shaped cylindrically to be welded around in its axis, a speed control unit to set the welding speed, an encoder to achieve the angular position information of the welding point where the laser camera gets material profile, a PLC to control the system and an industrial PC having IEEE1394 interface to monitor and manage the welding process.

Performing of the Cylindrical Welding Technique on Metal Pieces by the help of PLC control unit, the cylindrical welding technique is realized in the determined sequence. Torch is first positioned to the approximate starting points. Then, with the help of LPS sensors, the correct position of the torch is achieved. After the correct positioning, the welding starts. Rotation and welding occur at the same time. LPS sensors continuously feedback the correct position of the torch as position errors can happen due to the rotation of the welding piece. While one LPS checks for the actual torch position, the other LPS checks for the already made welding mark. After the full rotation, which can be understood by the feedback of the encoder, welding operation stops and the finished metal piece is released. The control algorithm flow chart for determination of the torch position of the welding point using LPS1 and LPS2 sensors is explained in Fig. 2. The control algorithm for PLC programming is shown in Figure 3. Since the specifications of the material to be welded in this operation are known, the coordinates of the welding torch are recorded on PLC and welding operation is started automatically.

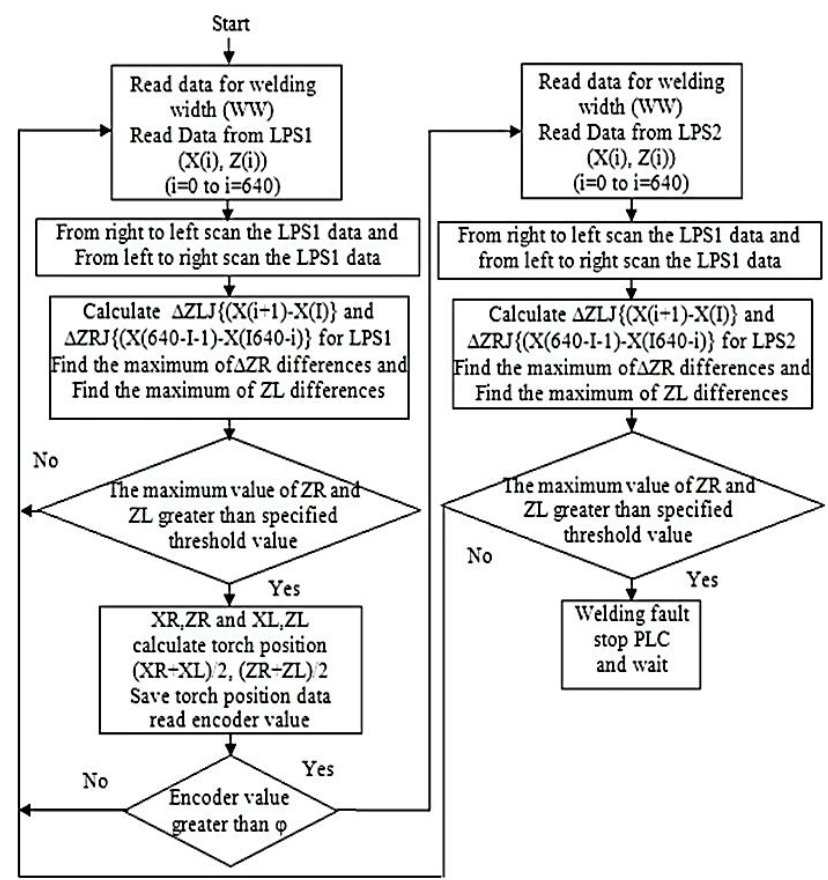

Figure 2 Algorithm for determining torch position welding point using LPS1 and LPS2 sensors

The torch coordinates for the work-pieces at different sizes are recorded to PLC as well, so that these coordinates can be selected for welding operations of work-pieces. 
There is a distance between the surface data obtained from LPS and the actual position of the welding torch. The distance between the welding torch and LPS can be tracked from the encoder showed by Özcan [11].

Table 1 Specifications of the Micro Epsilon LIt27×0-25 2d Laser Profile Sensor

\begin{tabular}{|c|c|c|c|c|}
\hline & Item & $\begin{array}{l}\text { Spec } \\
\mathrm{mm}\end{array}$ & Item & Spec. \\
\hline \multirow{3}{*}{ 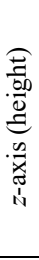 } & $\begin{array}{l}\text { Start of } \\
\text { measuring } \\
\text { range }\end{array}$ & 90 & $\begin{array}{l}\text { Resolution } \\
x \text {-axis }\end{array}$ & 640 points/profile \\
\hline & Midrange & 102,5 & $\begin{array}{c}\text { Profile } \\
\text { frequency }\end{array}$ & $100 \mathrm{~Hz}$ \\
\hline & $\begin{array}{c}\text { End of } \\
\text { measuring } \\
\text { range }\end{array}$ & 115 & Laser class & $2 \mathrm{M}: \lambda=658 \mathrm{~nm}$ \\
\hline \multirow{3}{*}{ 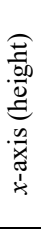 } & $\begin{array}{c}\text { Start of } \\
\text { measuring } \\
\text { range }\end{array}$ & 23 & $\begin{array}{l}\text { Operating } \\
\text { temperature }\end{array}$ & $0^{\circ} \mathrm{C}$ to $+50^{\circ} \mathrm{C}$ \\
\hline & Midrange & 25 & Protection class & IP 64 \\
\hline & $\begin{array}{c}\text { End of } \\
\text { measuring } \\
\text { range }\end{array}$ & 27 & Linearity 1 & $\pm 0.2 \%$ FSO $(3 \mathrm{~s})$ \\
\hline
\end{tabular}

When the distance is traversed, location information of the welding torch is transmitted over the encoder to the PLC which then resets the position of the welding torch to the recorded coordinates applied by Özcan et al. [22, 23]. The specifications of the Micro Epsilon LLT27 $\times 0-252 \mathrm{D}$ LPS used during the welding operation of the metal pieces are given in Tab. 1.

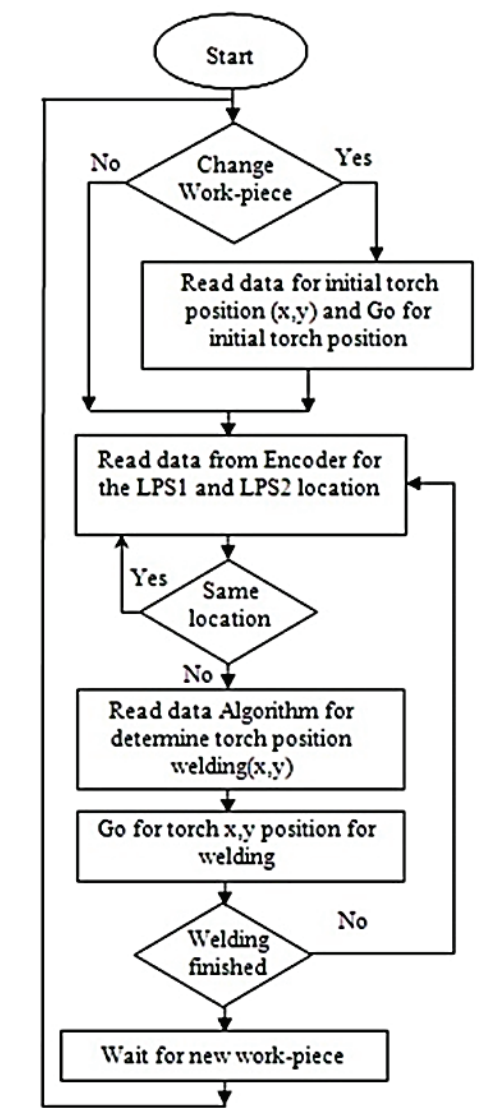

Figure 3 Control algorithms for PLC programming

The first LPS is used for the determination of the welding position at the initial stage and the second LPS is used for the detection of the possible welding errors to get the high quality weld performance.

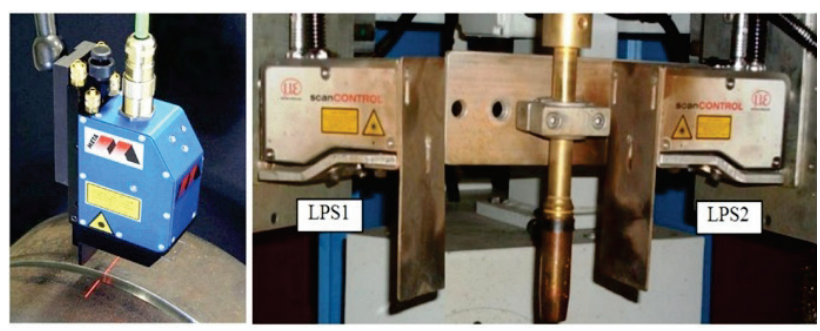

Figure 4 LPS1 and LPS2 sensors for welding torch after several testings (LPS1 protection set was rotated to be seen.)

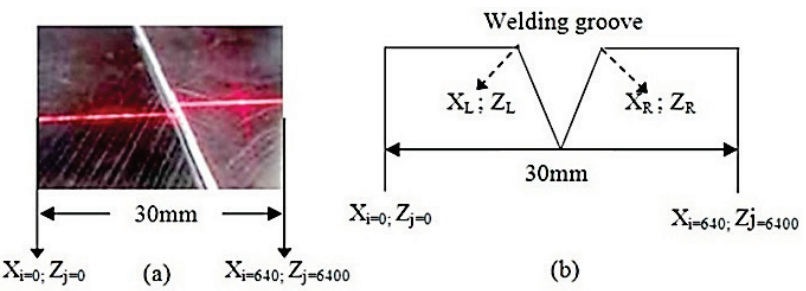

Figure 5 Material surface tracked by LPS1 (a) and welding work piece surface coordinates using LPS surface images (b)

The cylindrical welding parameters related to the thickness of the work-piece for two items are given in Tab. 2. The cylindrical materials are welded using 20 psi (Pounds per Square Inch) argon gas and $\mathrm{CO}_{2}$ as the protective gases.

Traditional manual welding has many disadvantageous over cylindrical welding technique such as excessive deformations due to the overlaps, roughness and faulty welding operation. Consequently, it comes up undesired poor welding performance. From these reasons, essential extra correction processes have to be done after the manual welding operation in order to get high quality production. On the other hand, the proposed alternative cylindrical welding technique occurs automatically and all the mentioned disadvantages of the manual welding can be eliminated by means of this technique. In addition to this, extra energy consumption caused by the manual welding operation is reduced. Therefore, the production costs of the welding processes can be diminished significantly and harmful gases such as $\mathrm{CO}_{2}$ applied during the manual welding for the protection of the operator can be totally eliminated. PLC unit and the welding torch, which includes the LPS sensors, are shown in Figs. 4-6.

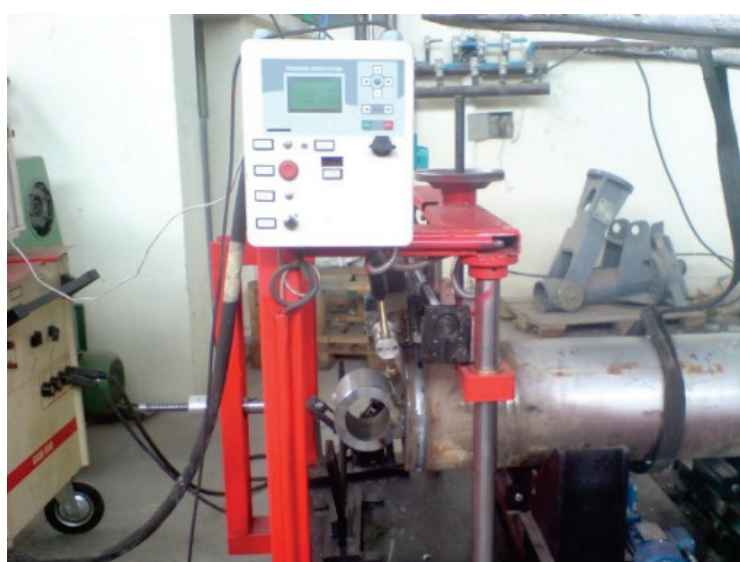

Figure 6 PLC unit and LPF including welding torch at the starting

The developed system and old traditional manual welding systems were compared with each other by welding two different diameters of the parts of $230 \mathrm{~mm}$ and 
$50 \mathrm{~mm}$. The larger diameter parts were used for visual inspection and the smaller diameter parts were used for tensile test comparison of welding quality. For determining the tensile properties of welded part specimens, $400 \mathrm{kN}$ Universal tensile test machine was used. The smaller diameter specimens were hydraulic cylinder seamless pipe, outer diameter $50 \mathrm{~mm}$ and the thickness is $5 \mathrm{~mm}$. The material of this pipe is ST52 steel whose tensile strength is $524 \mathrm{MPa}$ and Yield strength is $355 \mathrm{MPa}$. This ST52 steel is used to manufacture engineering machinery for plants, general buildings, etc., such as dumpers, mining trucks, excavators, loaders, bulldozers, coal mine hydraulic cylinders and supports, etc. The welding parameters used in process were given in Tab. 2. The welded part for the bigger diameter specimen was given in Fig. 7. The gases used during the welding process were measured and recorded with a Fluke 922/KIT 922 Air Flow Meter and the welding current was measured with Hantek PC Base USB Digital ampermeter.

Table 2 Cylindrical welding parameters related to the thickness of the workpiece

\begin{tabular}{|l|c|}
\hline \multicolumn{1}{|c|}{ Technical parameters for two items } & Specification \\
\hline Thickness of the work-piece $(\mathrm{mm})$ & 15 \\
\hline Wire feeder speed (mm / s) & 19 \\
\hline Welding speed (mm / s) & 5.5 \\
\hline Diameter of welding wire (mm) & 1.2 \\
\hline Welding current $(\mathrm{A})$ & 410 \\
\hline Shielded gas mix with $\mathrm{CO}_{2}$-ARGON $(\mathrm{L} / \mathrm{min})$ & 15 \\
\hline
\end{tabular}

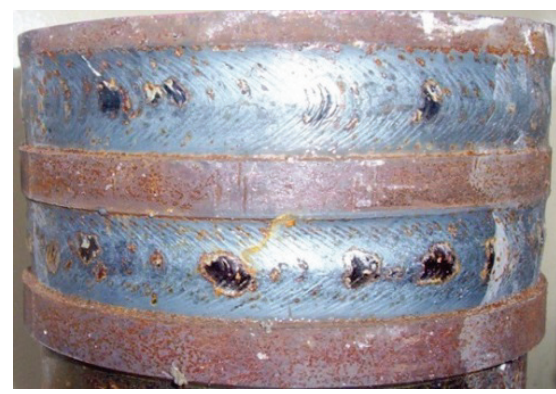

Figure 7 The final product using welding manipulator

\section{RESULTS AND DISCUSSION}

The applied welding technique is a more suitable and useful welding method than traditional welding technique such as human hand welding for metal pieces having a cylindrical shape. Therefore, it has been implemented for the welding operation of the cylindrical materials. For this purpose, a welding manipulator including a MIG welding machine; a biaxial stepper motor to control the position of the welding torch; a speed control unit to set the welding speed; a PLC to control, command, and actuate the whole system; and 3-phase motor to move the torch mechanism throughout the $x$-axis and $z$-axis were implemented.

There are two main reasons why we need to apply the cylindrical welding technique. The first reason is to increase the welding quality by eliminating human errors and minimizing the production costs. The second reason is to reduce the energy consumption during the welding processes. Additionally, the harmful gases are not released to the atmosphere and the operators will not be exposed to these hazardous gases emerging from the welding operation since they are not widely used. Thanks to the self-welding manipulator and other used equipment, the quality of the welding operation will be the same for all the processes.
According to the visual inspection and test results, this "Double Seam Profile Tracking Automation Method" seems to be superior to the manual welding system. Comparisons made at the hydraulic pipe welding (Fig. 7) are as follows. Compared with the welding time, it was seen that there was a decrease of $8.1 \%$ at the welding time. It is observed that there is a decrease of $8.5 \%$ in the gas usage volume measured by the flow meter during the experiments. It can be said that this improvement is caused not only because of the improvement in the welding utilization but also because of the interminent welding situation during operation. The interminent welding operation causes a waste gas volume for all triggering the welding torch. It was determined that the amount of electric energy used during welding was $10.3 \%$ less than the conventional method. This is due to the fact that the torch position is located very precisely relative to the part surface-welding groove, so that the arc and heat are efficiently produced. As the torch position changes continuously in the manual welding, it can be said that an insufficient melting or short circuit occurred instantaneously.

The reason for the $2.7 \%$ decrease in electrode mass is that the welding filler control is due to the precise adjustment of the feed rate and torch position. In this way, it is possible to save the weld metal mass by reducing the excessive crowned weld seam which has no strength in the part. Tensile tests were performed on small diameter pipes welded to the forehead. The maximum tensile strength was determined to be $6 \%$ higher than that of hand welded parts. There is little penetration in the hand welding and the intermittent welding between the welding seams was caused by the air gaps. When visual inspection of both welding methods is done, welding automation is seen to provide a very smooth and perfect weld seam. With the new welding technique less dross, less flaw, and smoothed seam profile were obtained on the welding seam. The comparison results are depicted in Tab. 3 .

Table 3 Comparison of the advantages of the double-seam profile laser-assisted system compared to the manual welding system

\begin{tabular}{|l|l|}
\hline \multicolumn{1}{|c|}{ Compared Specification } & \multicolumn{1}{c|}{ Reduction } \\
\hline Welding time & Reduced $8.1 \%( \pm 1.2)$ \\
\hline Welding shield gas consumption & Reduced $8.5 \%( \pm 1.5)$ \\
\hline Welding electrical energy consumption & Reduced $10.3 \%( \pm 1.6)$ \\
\hline Welding electrode wire mass & Reduced $2.7 \%( \pm 0.8)$ \\
\hline Tensile strength of welding parts & Increased strength $6 \%$ \\
\hline Visual welding quality & $\begin{array}{l}\text { Less dross, less flaw, } \\
\text { smoothed seam profile. }\end{array}$ \\
\hline
\end{tabular}

The electrode wire mass decreasing can be cited to unnecessary filling volume up to welding seam. The strength of the welded part was measured by universal tensile test by using prepared tensile test specimen. The tensile strength of the part was increased up to $6 \%$. It means the welding penetration is deeper and more efficient than manual welding.

\section{CONCLUSION}

The performance of the presented cylindrical welding technique by determining double seam profile tracking is found to be more efficient and precise in comparison to the traditional welding methods done by a welding operator.

With this new technique, all the necessary metal pieces having cylindrical shapes can be welded with minimum 
faults by using two laser sensors; and maximum weld quality is obtained during the operation processes. With the help of the presented cylindrical welding technique, not only the energy and time usage were reduced but also the large amount of $\mathrm{CO}_{2}$ emission to the atmosphere was significantly prevented. This is crucial for a clean environment with the purpose of controlling and minimizing of the global warming and climate changing. On the other hand, applying this technique instead of the industrial welding robot arms is much more economical because of the high costs of purchasing and maintaining those robots. It is believed and hoped that this study will be beneficial especially for the car and its subsidiary industry to help and improve their production quality. Particularly, this new technique will be indispensable to the hydraulic cylinder, pressure vessels and pipes and mobile crane manufacturing sector.

\section{Acknowledgement}

The authors would like to express their sincere thanks to MPG Machinery Production Group Inc. Co. and to the Necmettin Erbakan University Scientific Research Projects Office for its contribution to this study.

\section{REFERENCES}

[1] Rose, A., Benavides, J., Lim, D., \& Fria. O. (1996). Global warming policy, energy, and the Chinese economy. Res. and Ener. Eco., 18, 31-63. https://doi.org/10.1016/0928-7655(95)00018-6

[2] Kaygusuz, K. (2009). Energy and environmental issues relating to greenhouse gas emissions for sustainable development in Turkey. Ren. and Sust. Ener. Rev., 13, 253270. https://doi.org/10.1016/j.rser.2007.07.009

[3] Endiz, M. S., Özcan, M., Erişmiş, M. A., Yağc1, M., \& Günay, H. (2015). The simulation and production of glow plugs based on thermal modeling. T. J. of Elec. Eng. \& Comp. Sci., 23(1), 2197-2207. https://doi.org/10.3906/elk-1307-5

[4] Jacobson, M. Z. \& Delucchi, M. A. (2009). A path to sustainable energy by 2030. Sci. Amer., 301(5), 58-65. https://doi.org/10.1038/scientificamerican1109-58

[5] Bull, S. R. (2001). Renewable energy today and tomorrow. Proc. of the IEEE, 89(8), 1216-1226. https://doi.org/10.1109/5.940290

[6] Gülenç, B., Develi, K., Kahraman, N., \& Durgutlu, A. (2005). Experimental study of the effect of hydrogen in argon as a shielding gas in MIG welding of austenitic stainless steel. Int. J. of Hyd. Ener., 30(13), 1475-1481. https://doi.org/10.1016/j.ijhydene.2004.12.012

[7] Akorede, M. F., Hizam, H., Ab Kadir, M. Z. A., Aris, I., \& Buba. S. D. (2012). Mitigating the anthropogenic global warming in the electric power industry. Ren. and Sust. Ener. Rev., 16(5), 2747-2761. https://doi.org/10.1016/j.rser.2012.02.037

[8] Reichelt, W. R., Evancho, J. W., \& Hoy, M. G. (1980). Effects of shielding gas on gas metal arc welding aluminum. Welding J., 59(5), 147S-155S.

[9] Frazier, W. E. (2014). Metal additive manufacturing: a review. J. of Mater. Eng. and Perf., 23(6), 1917-1928. https://doi.org/10.1007/s11665-014-0958-z

[10] Zhao, H. \& Debroy, T. (2001). Weld metal composition change during conduction mode laser welding of aluminum alloy 5182. Met. and Mater. Trans. B, 32(1), 163-172. https://doi.org/10.1007/s11663-001-0018-6
[11] Özcan, M. (2011). Determining seam profile tracking of very narrow butt welding on sheet metal. Scientific Research and Essays, 6(23), 5040-5048.

[12] Jang, J. H., Chung, W. J., Jung, J. S., Jung, S. H., \& Lee, D. S. (2012). RSM-based Optimal Design of a Supporting base for Overlay Welding Automation System (OWAS) of Large L-type Tube. Presented at International Conference on Mechatronics and Automation, Chengdu, China. https://doi.org/10.1109/ICMA.2012.6282815

[13] Moser, M., Pfeiffer, M., \& Pichler, J. (2014). A Novel Domain-Specific Language for the Robot Welding Automation Domain. Presented at Emerging Technology and Factory Automation (ETFA), IEEE Barcelona, Spain. https://doi.org/10.1109/ETFA.2014.7005348

[14] Liu, Y. K. \& Zhang, Y. M. (2017). Supervised Learning of Human Welder Behaviors for Intelligent Robotic Welding. IEEE Trans. on Aut. Sci. and Eng., 14(3), 1532-1541. https://doi.org/10.1109/TASE.2015.2453351

[15] Takano, K., Koizumi, N., Serizawa, H., Tsubota, S., \& Makino, Y. (2017). Development of laser welding technology for fully austenitic stainless steel. Welding International, 31(11), 827-836. https://doi.org/10.1080/09507116.2016.1223221

[16] Sertić, J., Samardžić, I., Kozak, D., Šimunić, D., Gelo, I., \& Bučević-Keran, D. (2015). Influence of fatigue impact loading on radial carrier and rapping device fillet weld strength. Tehnički vjesnik, 22(2), 547-555. https://doi.org/10.17559/TV-20141022092231

[17] Tušek, J. (2002). Factors Affecting Weld Shape in Welding With a Triple-Wire Electrode. Metalurgija, 41(2), 89-92.

[18] Wang, H., Wang, D., Cheng, F., \& Wang, Y. (2015). A mechanism analysis of transverse weld cracks of marine thick steel plate. Tehnički vjesnik, 22(2), 289-296. https://doi.org/10.17559/TV-20150310112039

[19] Rojko, D. \& Gliha, V. (2005). The Influence of Simulated Thermal Cycle on the Formation of Microstructures of Multi-Pass Weld Metal. Metalurgija, 44(1), 19-24.

[20] Draganjac, I., Mutka, A., Kovačić, Z., Postružin, Ž., \& Munk, R. (2009). Design and Implementation of Remote Control System for Reactor Vessel Weld Inspection Manipulator. Automatika, 50(3-4), 215-226.

[21] Dunđer, M., Ivandić, Ž., \& Samardžić, I. (2008). Selection of arc welding parameters of micro alloyed HSLA steel. Metalurgija, 47(4), 325-330.

[22] Özcan, M., Endiz, M. S., \& Alver, V. (2015). A New Approach to the Boom Welding Technique by Determining Seam Profile Tracking. Int. J. of Adv. in Mech. \& Auto. Eng. (IJAMAE), 2(1), 31-34.

[23] Özcan, M. (2014). Design and realization of a welding oscillator. Turkish J. of Elect. Eng. \& Comp. Sci., 22(5), 1219-1229. https://doi.org/10.3906/elk-1212-28

Contact information:

Muciz ÖZCAN, Assoc. Prof. Dr

University of Necmettin Erbakan,

Faculty of Engineering, Dept. of Electric-Electronic

Koycegiz Campus/Meram, Konya-Türkiye

E-mail: mozcan@konya.edu.tr

Ahmet SAMANCl, Assoc. Prof. Dr.

University of Necmettin Erbakan,

Faculty of Aeronatical, and Space Sci. Dept. of Aeronatical.

Koycegiz Campus/Meram, Konya-Türkiye

E-mail: asamanci@konya.edu.tr

Ahmet CAN, Assist. Prof. Dr. (Corresponding Author)

University of Necmettin Erbakan,

Faculty of Engineering, Dept. of Industrial Design

Koycegiz Campus/Meram, Konya-Türkiye

E-mail: ahmetcan@konya.edu.tr 